\title{
Impact Compression Test on Concrete after High-Temperature Treatment and Numerical Simulation of All Feasible Loading Rates
}

\author{
Yue ZHAI, Yi LIU, Yubai LI, Yan LI, Yunmei SHI, KI-IL SONG
}

\begin{abstract}
Concrete materials are important in infrastructure and national defence construction. These materials inevitably bear complicated loads, which include static load, high temperature, and high strain rate. Therefore, the dynamic responses and fragmentation of concrete under high temperatures and loading rates should be investigated. However, the compressive properties of rock materials under ultrahigh loading rates $(>20 \mathrm{~m} / \mathrm{s})$ are difficult to investigate using the split Hopkinson pressure bar. Impact compression tests were conducted on concrete specimens processed at different temperatures $\left(20-800{ }^{\circ} \mathrm{C}\right)$ under three loading rates in this study to discuss the variation law of the impact compression strength of concrete materials after high-temperature treatment. On this basis, numerical simulation was conducted on impact compression test under all feasible loading rates $(10-110 \mathrm{~m} / \mathrm{s})$. The results demonstrate that the peak stress of all concrete specimens increases linearly with loading rate before $21 \mathrm{~m} / \mathrm{s}$ and gradually decreases after $21 \mathrm{~m} / \mathrm{s}$. Peak stress shows an inverted V-shaped variation law. Moreover, the temperature-induced weakening effect exceeds the strengthening effect caused by loading rate with the increase in temperature. The growth of peak stress decreases considerably, especially under an ultrahigh loading rate (>50 $\mathrm{m} / \mathrm{s}$ ). These conclusions can provide theoretical references for the design of the ultimate strength of concrete materials for practical applications, such as fire and explosion prevention.
\end{abstract}

Keywords: concrete; high loading rate; numerical simulation; SHPB; thermal treatment

\section{INTRODUCTION}

Concrete materials face numerous threats, such as fire disasters, explosions, earthquakes, and violent attacks, due to the increasingly complicated service environment of concrete structures and increasing demands of special structures (e.g., national defence and nuclear power). Therefore, the durability and stability of concrete materials are challenged under high temperatures and loading rates. As a typical heterogeneous brittle material, concrete is mixed with multiple ingredients and gradually hardens through hydration. Many microcracks, holes, and soft media are produced in concrete materials. The mechanical properties of concrete materials are complicated under high temperatures and impact loading. Therefore, studying the mechanical responses of concrete materials under strong dynamic loads not only provides an important theoretical basis for reasonable analyses and design of safe concrete structures but also avoids serious casualties and property losses during disastrous accidents.

The split Hopkinson pressure bar (SHPB) test system is widely used in experimental studies on the dynamic mechanical properties of rock materials. Researchers worldwide have investigated concrete materials by using SHPB [1-3], and the impact loading rate of large-diameter bullets $(37-120 \mathrm{~mm})$ can be generally controlled within a certain range $(<20 \mathrm{~m} / \mathrm{s})$ due to the limited strength and rigidity of the pressure bar materials in SHPB [4-6] Ultrahigh-speed impact failure occasionally occurs in multiple accidents and international safety events. Hence, the relevant laws of the mechanical properties of engineering materials under ultrahigh loading rates should be investigated. Numerical simulation based on testing is a good supplementary research method [7].

The variation laws of the impact compression strength of concrete materials after high-temperature treatment under all feasible loading rates $(10-110 \mathrm{~m} / \mathrm{s})$ were investigated in this work through testing and numerical simulation. This study aims to provide theoretical references for the design of the ultimate impact compression strength of concrete projects under high temperatures and impact loads.

\section{STATE OF THE ART}

Many experimental studies have been conducted on the dynamic mechanical properties of concrete and other rock materials after high-temperature treatment [8-14]. $\mathrm{Zhu}$ et al. conducted a uniaxial compression test on sandstone at $25-800{ }^{\circ} \mathrm{C}$ and found that the volume of sandstone gradually increased, whereas its mass and density gradually decreased with the increase in temperature [8]. The peak stress gradually increased with the increase in temperature from $25{ }^{\circ} \mathrm{C}$ to $400{ }^{\circ} \mathrm{C}$ then decreased after $585^{\circ} \mathrm{C}$. Li et al. [9] and Fan et al. [10] performed an SHPB test on granite materials after hightemperature treatment $\left(25-800{ }^{\circ} \mathrm{C}\right)$ and found a negative linear relationship between the dynamic strength of granite and temperature. However, the dynamic strength of granite increased with the increase in impact pressure. The adsorption capacity of dynamic energy gradually increased with the increase in temperature before $400{ }^{\circ} \mathrm{C}$, but an opposite variation law was observed with the increase in temperature from $400{ }^{\circ} \mathrm{C}$ to $800^{\circ} \mathrm{C}$. Li et al. [12] and Chen [13] analyzed concrete materials under $20-900{ }^{\circ} \mathrm{C}$ and $3-$ $20 \mathrm{~m} / \mathrm{s}$ and discovered a negative linear relationship between the dynamic strength of concrete and temperature. In addition, the dynamic strength of concrete increased as the impact pressure increased. Xiao et al. tested highstrength concrete under the temperature range of $20-800^{\circ} \mathrm{C}$ [14]. They found that the number of cracks and fragments was positively related to temperature and strain rate. These studies have confirmed that loading rate within a certain range can remarkably strengthen the mechanical properties of rock materials under a fixed temperature. Experimental studies that are supplemented and verified by corresponding numerical simulations and relevant achievements have been approved by engineering and academic circles [15-20]. Jiang et al. conducted a numerical simulation of argillaceous siltstone at a loading 
rate of $12-21 \mathrm{~m} / \mathrm{s}$ by using ANSYS/LS-DYNA and reported that the fragmentation of materials began at the edges and propagates to the centre. The peak strength of specimens increased with the increase in impact speed [18]. Ai et al. performed a numerical simulation on polyurethane (PU) polymer concrete specimens at a loading rate of $5-21 \mathrm{~m} / \mathrm{s}$ and found that the dynamic compressive strength of concrete initially increased then decreased with the increase in loading rate [19]. These studies were based on tests and numerical simulation under a conventional loading rate. However, only a few research achievements have been reported under ultrahigh loading rates. Han et al. performed a numerical simulation analysis of grey packed sand at an ultrahigh loading rate $(25-55 \mathrm{~m} / \mathrm{s})$ to determine the relationship between peak stress and high loading rate [20]. They indicated that the peak tensile load and peak strain of specimens gradually increased with the increase in impact speed. This study overcame the limitation of the SHPB system and provided a research idea for the peak stress of concrete materials under ultrahigh loading rates. However, this study was not supported by mutual verification via experimental study and numerical simulation and did not consider the weakening effect caused by thermal injuries.

An SHPB test was conducted on concrete specimens at room temperature $\left(20{ }^{\circ} \mathrm{C}\right)$ in the present study. The specimens were subsequently processed under $400{ }^{\circ} \mathrm{C}, 600$ ${ }^{\circ} \mathrm{C}$, and $800{ }^{\circ} \mathrm{C}$ and at different loading rates $(8.6,14.2$, and $18.4 \mathrm{~m} / \mathrm{s}$ ). On the basis of the test results, a numerical simulation analysis was performed under a corresponding loading rate. The simulation analysis results were compared with the test results, which can be used to determine reasonable simulation parameters. Subsequently, a numerical simulation analysis based on an SHPB test under all feasible loading rates of $20-110 \mathrm{~m} / \mathrm{s}$ was conducted to determine the peak stress of different concrete specimens and its correlation with loading rate.

The remainder of this study is organized as follows. Section 3 introduces the test specimens, equipment, and the numerical simulation modelling. Section 4 analyzes the test results and verifies the reliability of the numerical simulation. In addition, the influences of the fragmentation characteristics of concrete and all feasible loading rates on peak stress are evaluated. Section 5 summarizes the conclusions.

\section{EXPERIMENTS}

\subsection{Principle of the SHPB Uniaxial Test}

The SHPB device uses a high-pressure air pump to compress the gun barrel, which provides the impact bar a certain initial loading rate. The initial loading rate was measured with a laser velocimeter, and the impact bar impacted the incident bar at this rate, thereby producing an incident pulse. The incident pulse propagated in the pressure bar system. Reflected and transmitted waves were produced on the contact surfaces of the incident bar, transmission bar, and specimen. The specimen developed high-speed deformation during the loading process. Strain gauges attached on the incident and transmission bars recorded the corresponding impulse information, which was stored in the waveform memorizer by using an ultradynamic strain indicator. The structure of the SHPB device is shown in Fig. 1.

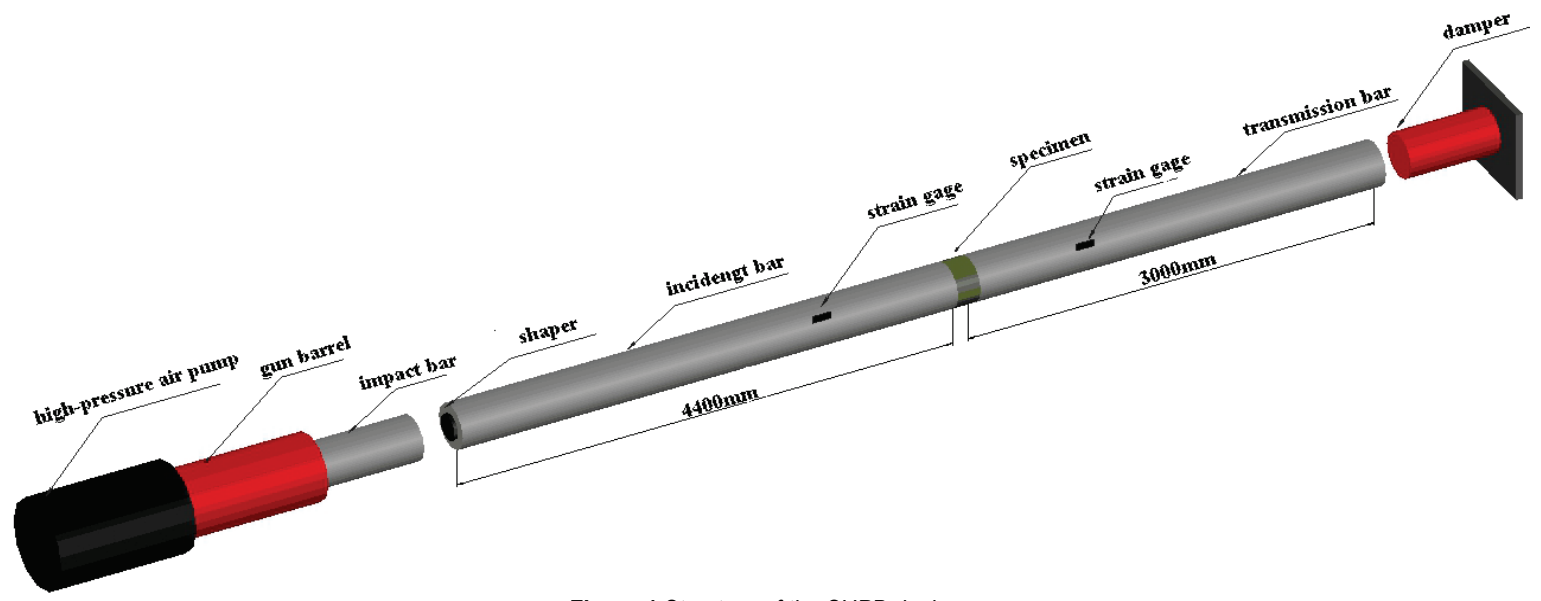

Figure 1 Structure of the SHPB device

According to the theory of 1D stress waves, the key parameters, such as dynamic stress, strain, and strain rate, of specimens can be deduced by incident, reflected, and transmitted impulses. The corresponding stress-strain curves were obtained. Displacements $\left(u_{1}, u_{2}\right)$ at the front and rear surfaces of the specimens in the test can be expressed as

$$
\begin{aligned}
& u_{1}=\int_{0}^{t} C_{0} \varepsilon_{1} \mathrm{~d} t \\
& u_{2}=\int_{0}^{t} C_{0} \varepsilon_{2} \mathrm{~d} t
\end{aligned}
$$

where $C_{0}$ is the elastic wave velocity of the bars and $\varepsilon_{1}$ and $\varepsilon_{2}$ are the strains of the front and rear surfaces, respectively. $\varepsilon_{1}$ includes the incident strain impulse $\left(\varepsilon_{i}\right)$ that propagates forward and the reflected strain impulse $\left(\varepsilon_{r}\right)$ that propagates backward. $\varepsilon_{2}$ is the transmitted strain impulse $\left(\varepsilon_{t}\right)$ that propagates toward the right. Therefore, the displacements of two surfaces can be expressed as

$$
\begin{aligned}
& u_{1}=\int_{0}^{t} C_{0}\left(\varepsilon_{\mathrm{i}}-\varepsilon_{r}\right) \mathrm{d} t \\
& u_{2}=\int_{0}^{t} C_{0} \varepsilon_{t} \mathrm{~d} t
\end{aligned}
$$


After the introduction of the homogeneity hypothesis, the calculation method is simplified into a two-wave method as follows:

$\varepsilon_{i}=\varepsilon_{r}+\varepsilon_{t}$

Therefore, the loads on the front and rear surfaces are

$$
\begin{aligned}
& P_{1}=E A\left(\varepsilon_{i}-\varepsilon_{t}\right) \\
& P_{2}=E A \varepsilon_{t}
\end{aligned}
$$

Therefore, the average strain of specimens can be expressed as

$\varepsilon_{s}=\frac{u_{1}-u_{2}}{L}=\frac{C_{0}}{L} \int_{0}^{t}\left(\varepsilon_{i}-\varepsilon_{r}-\varepsilon_{t}\right) \mathrm{d} t=-\frac{2 C_{0}}{L} \int_{0}^{t} \varepsilon_{r} \mathrm{~d} t$

The specimens developed deformation and shortened with the increase in the loading process. The deformation rate of specimens is the strain rate

$\dot{\varepsilon}=\frac{\mathrm{d} \varepsilon}{\mathrm{d} t}=-\frac{2 C_{0} \varepsilon_{r}}{L}$

The average stress of specimens is

$\sigma_{s}=\frac{P_{1}+P_{2}}{2 A_{s}}=\frac{E A}{2 A_{s}}\left(\varepsilon_{i}-\varepsilon_{r}+\varepsilon_{t}\right)=\frac{E A}{A_{s}} \varepsilon_{t}$

where $A_{S}$ is the cross-section area of the specimens, $L$ is the length of specimens, $E$ is the elasticity modulus of the bars, and $A$ is the cross-section area of the bars.

\section{TEST SPECIMENS AND EQUIPMENT}

C35\# concrete provided by a commodity concrete stirring station was used as the testing material. Portland cement (42.5\#) was applied. The coarse aggregate used limestone gravels with a grain size of $5-20 \mathrm{~mm}$, and the fine aggregate used medium sands with a cement content of approximately $10 \%$. In addition, $6.2 \%$ (mass fraction) fly ash, iron powder, and additives, such as water reducing agent, were added. The mixing ratios are listed in Tab. 1 [21]. The concrete materials were processed into $98 \mathrm{~mm}$ (diameter) $\times 50 \mathrm{~mm}$ (height) cylinder specimens.

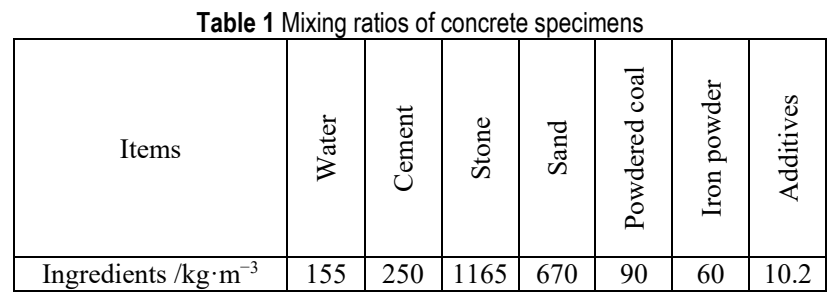

$* \mathrm{~kg} \cdot \mathrm{m}^{-3}$ represents the mass of each item per cubic meter concrete

An AI-518 intelligent temperature control device was used as the heating equipment in the test (Fig. 2). The effective size of the combustion chamber was $400 \times 200 \times 160 \mathrm{~mm}^{3}$, and the highest heating temperature was $1300{ }^{\circ} \mathrm{C}$. The specimens were preheated to reduce the influences of internal moisture in the fast heating process. During preheating, the voltage and preheating time were set to $75 \mathrm{~V}$ and $10 \mathrm{~min}$, respectively. The specimens were heated to the target temperatures $\left(400{ }^{\circ} \mathrm{C}, 600{ }^{\circ} \mathrm{C}\right.$, and 800 $\left.{ }^{\circ} \mathrm{C}\right)$. The heating curves are shown in Fig. 3. The specimens were constantly heated for $2 \mathrm{~h}$ under the target temperature to keep their internal and external temperatures consistent in consideration of the duration of ordinary fire disasters [22]. The heated specimens were removed and cooled under room temperature and natural ventilation.

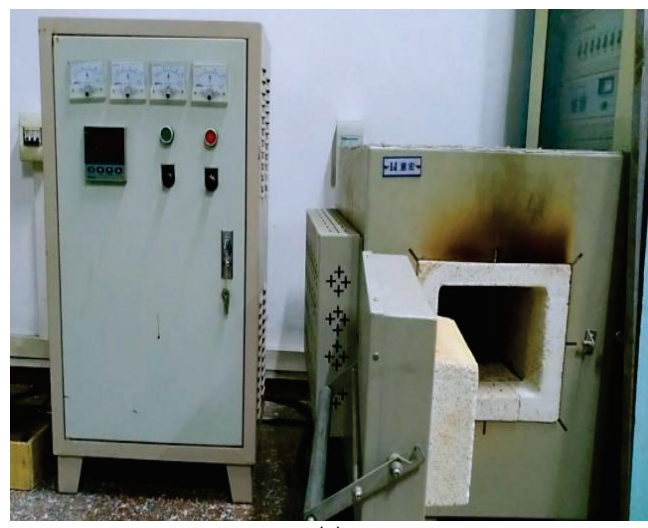

(a)

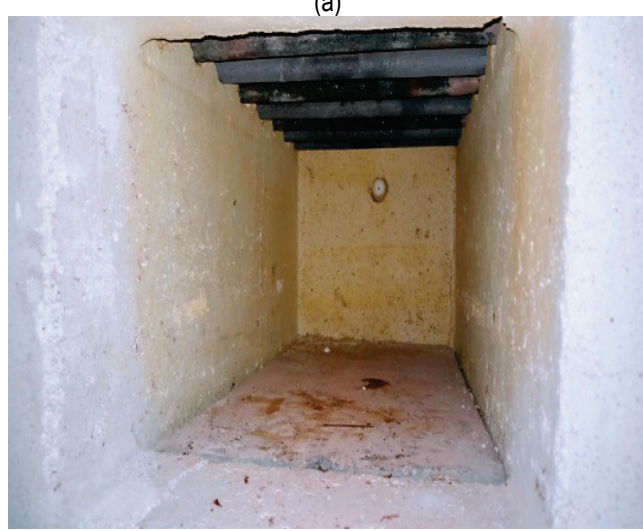

(b)

Figure 2 Intelligent temperature control device: (a) Monitoring chamber and heating furnace, (b) Internal structure of the heating furnace

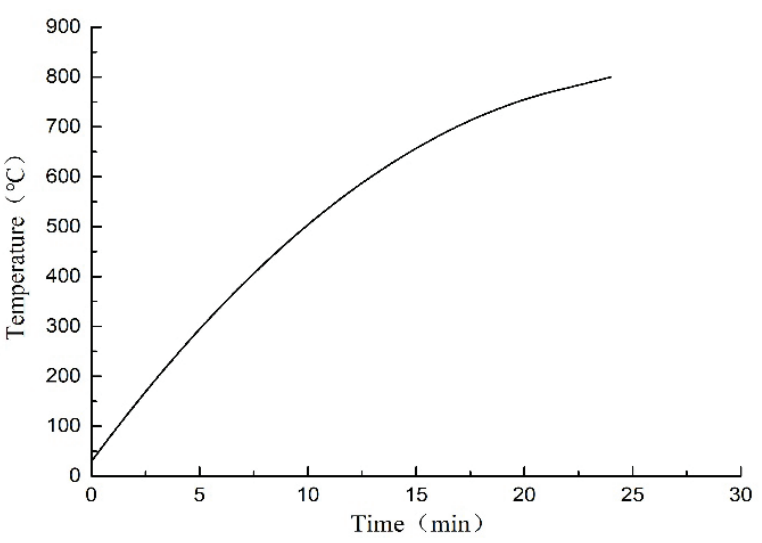

Figure 3 Heating curves

An SHPB system with a diameter of $100 \mathrm{~mm}$ was applied in the test (Fig. 4). The SHPB system was mainly composed of the loading device (air pump and gun barrel), compression bar system, energy absorption device, and test system. The compression bar system consisted of a 400 $\mathrm{mm}$ impact bar, a $4400 \mathrm{~mm}$ incident bar, and $3000 \mathrm{~mm}$ 
transmission bar. All bars were made of $45 \#$ steel with a density of $\rho_{0}=7850 \mathrm{~kg} / \mathrm{m}^{3}$ and elasticity modulus of $E=$ $210 \mathrm{GPa}$. The propagation speed of the stress wave in the bars was $c_{0}=\sqrt{E / \rho_{0}} \approx 5170 \mathrm{~m} / \mathrm{s}$.

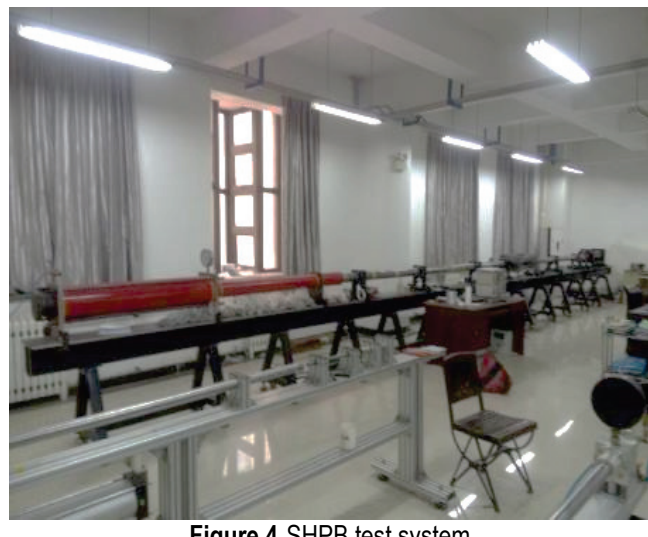

Figure 4 SHPB test system

The air pressures of the compressed air pump were controlled at $0.25,0.35$, and $0.5 \mathrm{MPa}$. The initial impact loading rates of the impact bar were $8.6,14.2$, and $18.4 \mathrm{~m} / \mathrm{s}$. After several specimen tests, $1.5 \mathrm{~mm}$ thick red copper sheets (diameter $=40 \mathrm{~mm}$ ) were used as the wave shaper of the stress wave. A comparison of stress waveforms before and after shaping is shown in Fig. 5, which indicates an ideal shaping effect.

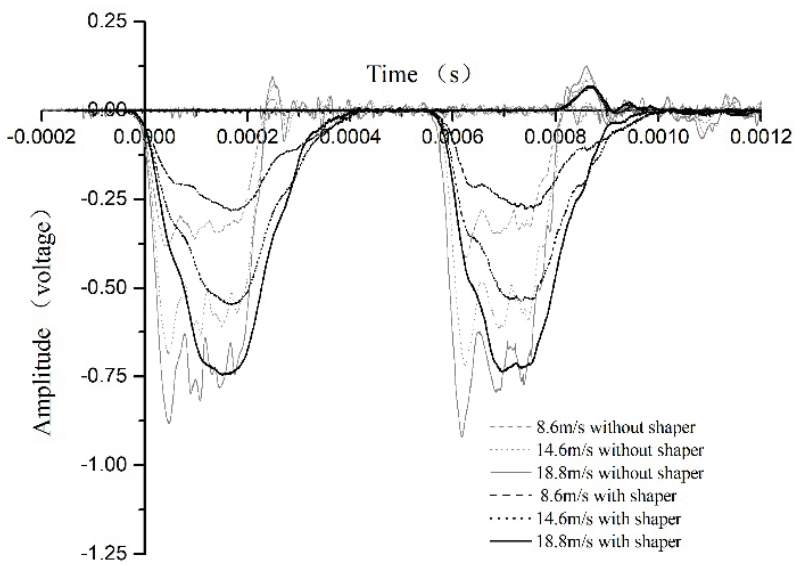

Figure $\mathbf{5}$ Waveforms before and after shaping under different air pressures

\subsection{SHPB Uniaxial Impact Test Modelling}

The thermal injuries of concrete materials and the key factors, such as stress wave, produced at the impact of the impact bar onto the incident bar were considered in the numerical simulation based on the SHPB test. ANSYS/LSDYNA finite element software, which is commonly used in explosive blast testing, was applied in the numerical simulation. Considering the initial thermal injuries of materials, the relevant mechanical parameters of concrete materials after high-temperature processing were inputted to the HJC model in the numerical simulation software [23]. The impact process was simulated directly by applying the initial loading rate of the impact bar, and the initial loading rate of the impact bar was defined by the keyword *INITIAL_VELOCITY. For the shaping of the incident wave, the red copper waveform shaper was directly simulated, and the constitutive model used a kinematic hardening model, that is, the PLASTIC KINEMATIC material model.

The constructed model was composed of four parts, namely, impact bar and waveform shaper, incident bar, test specimens, and transmission bar. The numbers of units in the geometric models of the four parts were 15,000, $165,000,30,000$, and 112,500 , respectively. The diameter and thickness of the concrete specimens were 98 and 50 $\mathrm{mm}$, respectively. The 3D finite element model is shown in Fig. 6.

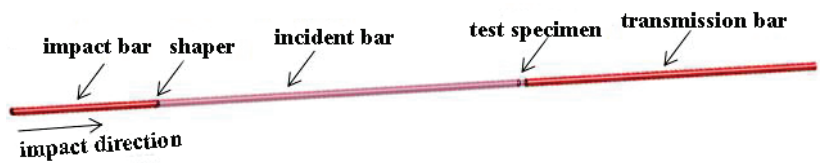

(a)

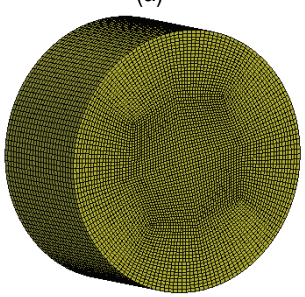

(b)

Figure 6 3D numerical model of the SHPB test. (a) Overall structure of the numerical simulation model in the SHPB test (b) Concrete specimen

\section{RESULT ANALYSIS AND DISCUSSION}

\subsection{Result Analysis of the SHPB Uniaxial Test}

The dynamic stress-strain curves of concrete specimens, which were processed under different temperatures and at the same loading rate, are shown in Fig. 7. The peak stress and peak strain of the concrete specimen processed under $400{ }^{\circ} \mathrm{C}$ were equal to or slightly higher than those of specimens processed under room temperature $\left(20^{\circ} \mathrm{C}\right)$. The peak stress of the concrete specimen processed under $400{ }^{\circ} \mathrm{C}$ was slightly lower than that of the specimen processed under room temperature. The peak stress and peak strain of the concrete specimen processed under $800{ }^{\circ} \mathrm{C}$ were low. This result indicates that the compression strength of concrete changes slightly with temperature in the range of $20-400{ }^{\circ} \mathrm{C}$ and decreases after $400{ }^{\circ} \mathrm{C}$. Therefore, $400^{\circ} \mathrm{C}$ can be used as the thermal injury threshold of this concrete material; the value is slightly higher than the threshold under static load (approximately $\left.300{ }^{\circ} \mathrm{C}\right)[24,25]$. Moreover, double peaks occurred in the specimens processed under high temperatures $\left(600^{\circ} \mathrm{C}\right.$ and $\left.800^{\circ} \mathrm{C}\right)$ and high loading rates $(14.2$ and $18.4 \mathrm{~m} / \mathrm{s})$. In other words, stress continues to increase to the second peak point after a small drop, and the curve is gradually lifted.

On the one hand, the "two-peak" phenomenon is caused by the serious thermal injuries of concrete specimens and the remarkable change in material properties, resulting in the serious mismatch between the impedance and bar system. No stress impulses or only a few can be transmitted to the transmission bar through the specimens, and most of the stress impulses can be reflected to the incident bar, thus forming the second peak [26, 27]. On the other hand, concrete is mixed with coarse aggregate, fine aggregate, and cement mortar through stirring. Concrete strength is generally and positively related to the proportions of aggregates due to the random addition of aggregates during the preparation of specimens and the certain relationship between concrete strength and 
proportion of aggregates. The stress-strain curves presented a single peak then a double peak.

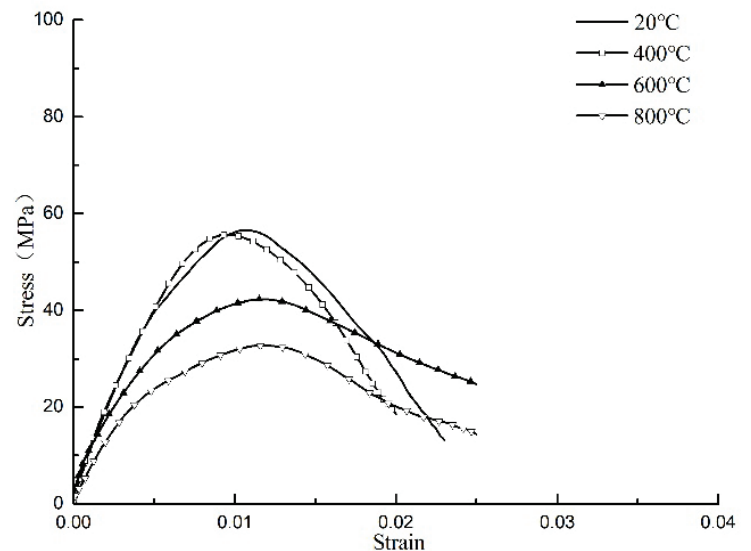

(a)

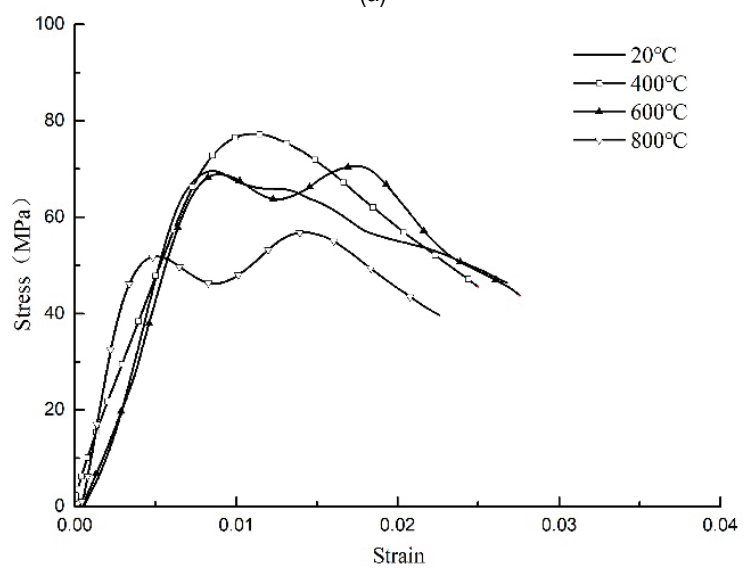

(b)

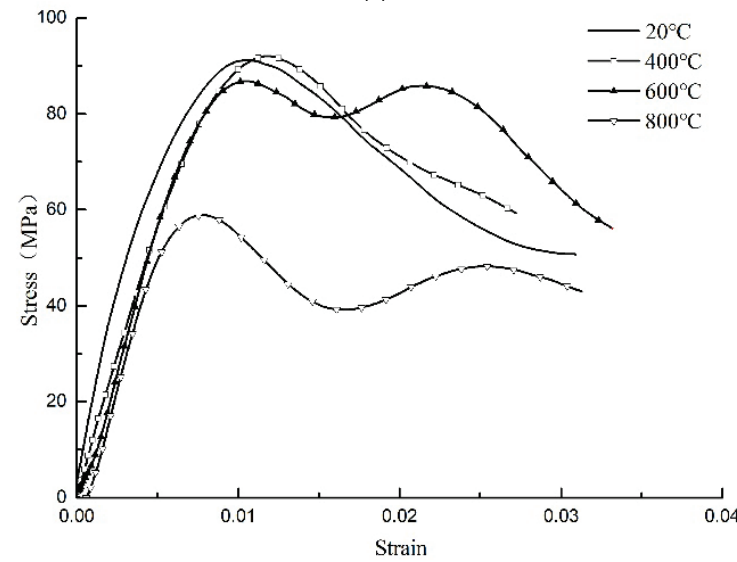

(c)

Figure 7 Stress-strain curves under the same impact loading rate but different temperature: (a) $8.6 \mathrm{~m} / \mathrm{s}$, (b) $14.2 \mathrm{~m} / \mathrm{s}$, (c) $18.4 \mathrm{~m} / \mathrm{s}$

Therefore, the two-peak phenomenon of the curves in Figs. 7(b) and 7(c) was related to the mass proportion of aggregates in the specimens. The strengthening effect of aggregates was reflected on the stress-strain curves, indicating that many peaks existed after the first peak. The stress-strain curve of all specimens was lifted up with the increase in the mass proportion of aggregates, and the curves were changed from softening to hardening. Moreover, the space structure of aggregates was compact and stable under a high mass proportion of aggregates. The stress-strain curve of concrete always changes within the lower and upper limits formed by the mass proportion of aggregates. This conclusion conforms to the test analyses of other researchers [28-33].

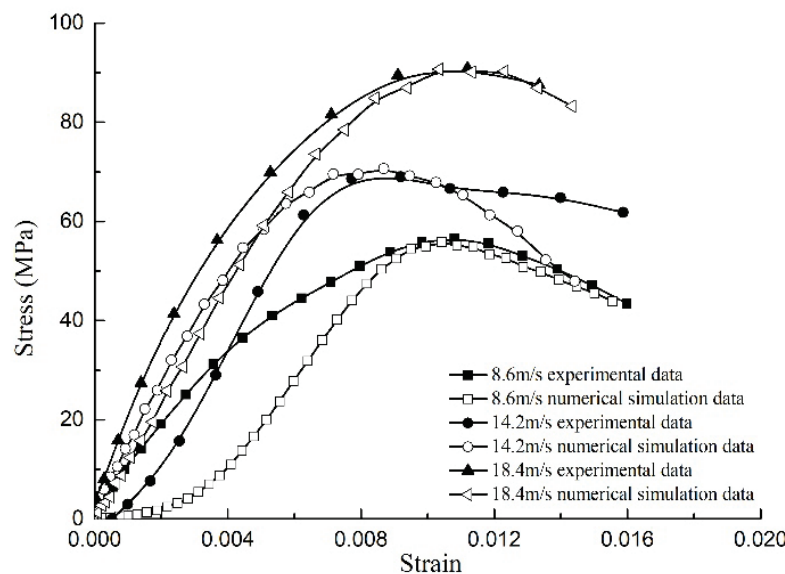

(a)

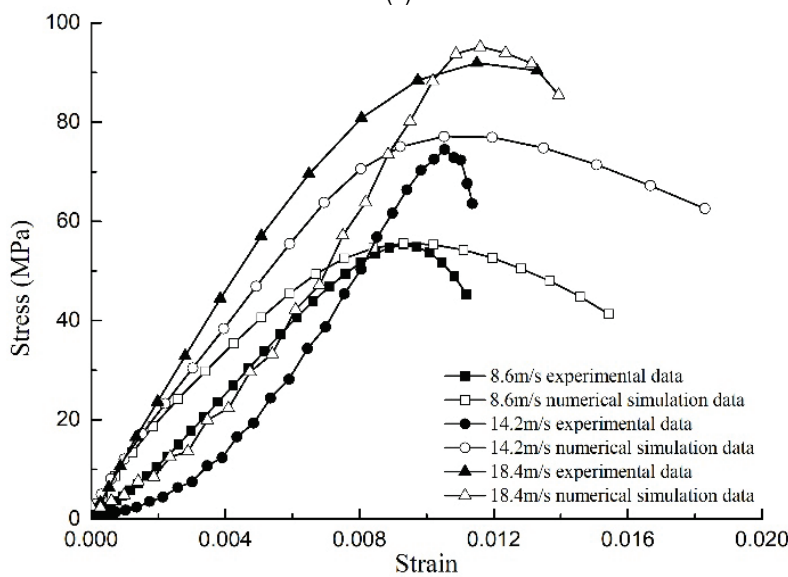

(b)

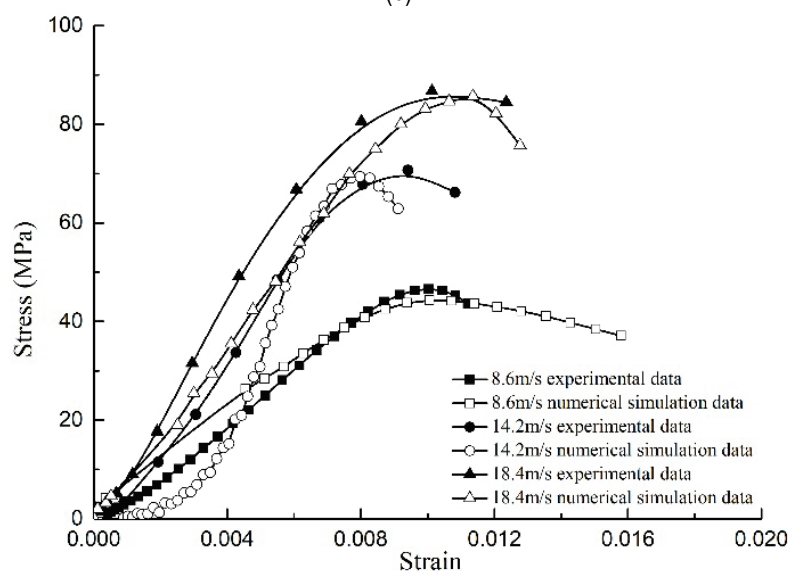

(c)

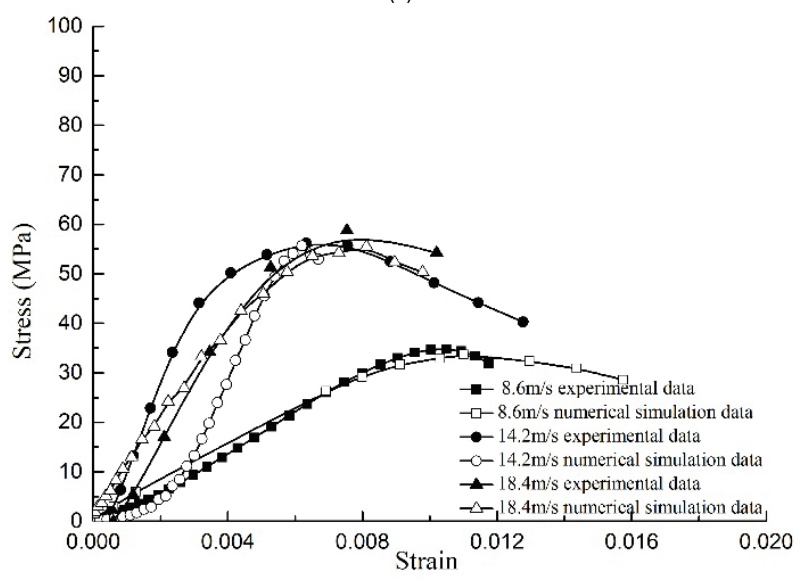

(d) 
Figure 8 Comparison of the numerical simulation and test stress-strain curves under the same temperature but different impact loading rates: (a) $20^{\circ} \mathrm{C}$, (b) $400^{\circ} \mathrm{C}$, (c) $600^{\circ} \mathrm{C}$, (d) $800^{\circ} \mathrm{C}$

\subsection{Reliability Analysis of Numerical Simulation}

A comparison of the numerical simulation and test stress-strain curves under the same temperature but different impact loading rates is shown in Fig. 8. The numerical simulation stress-strain curves of concrete under different impact loading rates showed good agreement. The peak stress error of specimens processed at or below $600{ }^{\circ} \mathrm{C}$ was approximately $5 \%$ under all loading rates. The peak stress error of specimens processed at $800{ }^{\circ} \mathrm{C}$ under a high loading rate $(18.4 \mathrm{~m} / \mathrm{s})$ was relatively high (approximately 8-12\%). The total error was smaller than $12 \%$, which further verifies the reliability of the numerical simulation method and parameter selection for the impact test.

\subsection{Fragmentation Characteristics of Concrete Specimens Under Uniaxial Compression Loads}

Numerical simulation can analyze results that are difficult to be obtained through tests, such as development laws of cracks, stress-strain redistribution, and fragmentation characteristics of specimens. In this numerical simulation, the fragmentation of typical concrete specimens processed under high temperatures and high loading rates was analyzed. Considering the presence of real-time changes in stress during numerical simulation, the stress clouds at different times differed. Therefore, the node with remarkable changes was used to analyze the variation laws of stress in the specimens during the fragmentation of concrete.

The distributions of the fragmentation degree, radial strain, and axial stress of the concrete specimen processed at $800{ }^{\circ} \mathrm{C}$ under $18.4 \mathrm{~m} / \mathrm{s}$ are shown in Figs. 9, 10, and 11 .

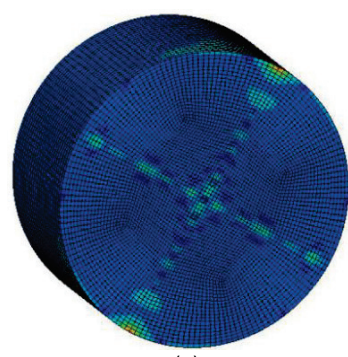

(a)

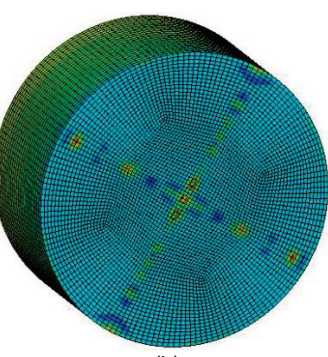

(b)
Figure 9 Radial strain and axial stress at initial cracking ( $t=883$ us): (a) Radial strain, (b) Axial stress

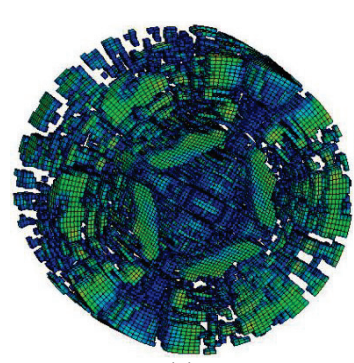

(a)

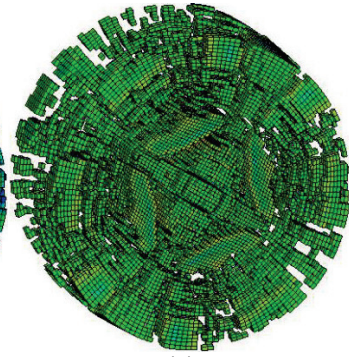

(b)
Figure 10 Radial strain and axial stress during crack development ( $t=1369 \mathrm{us}$ ): (a) Radial strain, (b) Axial stress

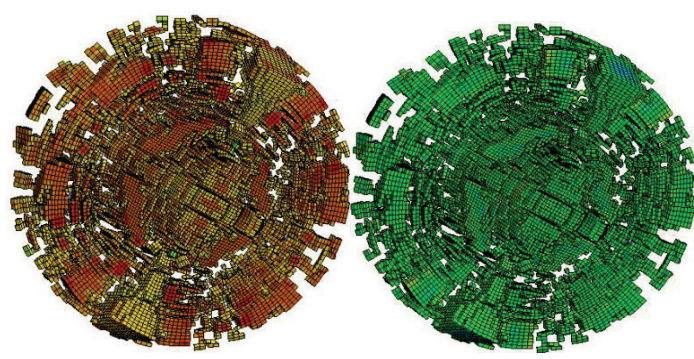

(a)

(b)

Figure 11 Radial strain and axial stress at the end of loading ( $t=2000 \mathrm{us}$ ):

(a) Radial strain, (b) Axial stress

\subsection{Effects of All Feasible Loading Rates on Peak Stress}

The pressure bars in the large-diameter bar system applicable to brittle materials, such as rocks, may be heated and may even develop deformation when the impact loading rate exceeds a certain range due to material limitations of SHPB, thereby destroying the test equipment. Therefore, the impact loading rate in the test cannot be remarkably increased. In this case, the advantages of numerical simulation are highlighted. The SHPB test on concrete specimens processed under different temperatures but different loading rates $(20,25$, $30,50,100$, and $110 \mathrm{~m} / \mathrm{s}$ ) was simulated after numerical simulation and test verification. On this basis, the variation curves of peak stress with loading rate were obtained (Fig. 12).

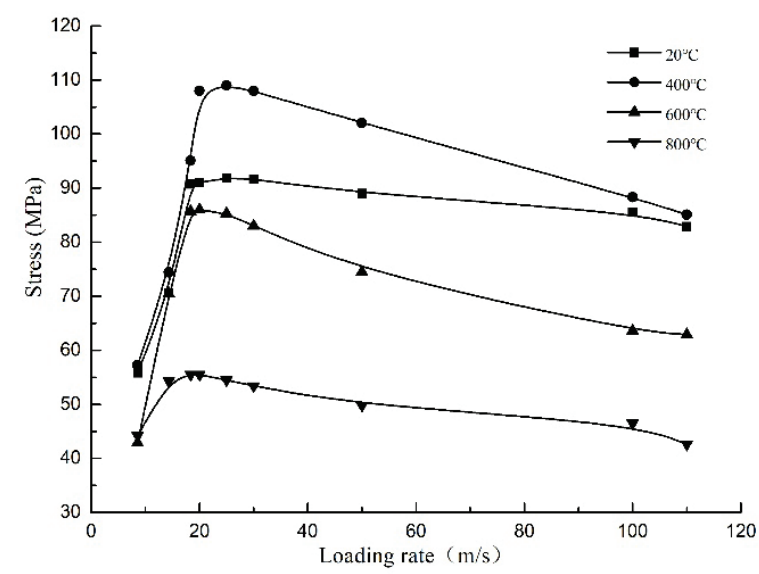

Figure 12 Changes in stress with loading rate under different temperatures

As shown in Fig. 12, the peak stress of concrete materials initially increased then decreased with the increase in loading rate rather than presenting a linear growth. In other words, the peak stress of concrete materials reached the maximum at approximately $21 \mathrm{~m} / \mathrm{s}$. Subsequently, the peak stress decreased with the increase in loading rate. This condition reveals that the loading rate threshold for the strain growth of concrete specimens processed at high temperatures was approximately $21 \mathrm{~m} / \mathrm{s}$ because the failure of concrete materials was mainly due to the initiation and development of internal microcracks. The impact energy was small because of the low loading rate $(10 \mathrm{~m} / \mathrm{s})$, which provided adequate time for the initiation and development of existing microcracks. However, a few new cracks, small interactions among cracks, and low stress level were observed, leading to a low peak stress. The impact energy was high under a high loading rate $(<21$ 
$\mathrm{m} / \mathrm{s}$ ), which facilitated the initiation, development, and combination of existing microcracks and promoted the development and combination of new microcracks. In addition, the cracks mutually interacted, and the stress level was high, thus resulting in high bearing capacity and high peak stress of materials. The propagation speed of new and old cracks remarkably increased with the increase in loading rate. Thus, cracks ran through the aggregates before bridging and combination. The energy dissipation response lagged behind the loading rate responses [34-36].
Thus, the growth strength of the concrete specimens decreased to some extent.

The numerical values of the peak stress of concrete specimens processed under high temperatures and different loading rates and their variation laws relative to those of specimens processed under room temperature were analyzed to determine the influences of thermal injuries on the relationship between the compression strength of concrete materials and loading rate (Tab. 2).

Table 2 Change rate of the peak stress of concrete specimens processed under different temperatures and different loading rates compared with that of specimens processed under $20^{\circ} \mathrm{C}$

\begin{tabular}{|c|c|c|c|c|c|c|c|}
\hline \multirow{2}{*}{$\begin{array}{c}\text { Loading rate } \\
(\mathrm{m} / \mathrm{s})\end{array}$} & \multirow{2}{*}{$\begin{array}{c}20^{\circ} \mathrm{C} \\
\text { Peak stress }(\mathrm{MPa})\end{array}$} & \multicolumn{2}{|c|}{$400^{\circ} \mathrm{C}$} & \multicolumn{2}{|c|}{$600^{\circ} \mathrm{C}$} & \multicolumn{2}{|c|}{$800^{\circ} \mathrm{C}$} \\
\hline & & Peak stress $(\mathrm{MPa})$ & Change rate $\%$ & Peak stress (MPa) & Change rate $\%$ & Peak stress $(\mathrm{MPa})$ & Change rate $\%$ \\
\hline 8.6 & 55.8 & 57.3 & 2.69 & 54.2 & -2.86 & 42.9 & -23.12 \\
\hline 14.2 & 70.6 & 74.4 & 5.38 & 70.5 & -0.14 & 54.3 & -23.09 \\
\hline 18.4 & 90.7 & 95.1 & 4.85 & 85.7 & -5.51 & 55.5 & -38.81 \\
\hline 20 & 91 & 108 & 18.68 & 86 & -5.49 & 55.5 & -39.01 \\
\hline 25 & 91.9 & 109 & 18.61 & 85.3 & -7.18 & 54.5 & -40.70 \\
\hline 30 & 91.7 & 108 & 17.78 & 83 & -9.49 & 53.4 & -41.77 \\
\hline 50 & 89 & 102 & 14.61 & 74.5 & -16.29 & 49.8 & -44.04 \\
\hline 100 & 85.5 & 88.3 & 3.27 & 63.9 & -25.26 & 46.5 & -45.61 \\
\hline 110 & 82.9 & 85.1 & 2.65 & 62.9 & -24.13 & 42.6 & -48.61 \\
\hline
\end{tabular}

The peak stress of the concrete specimen processed at $400{ }^{\circ} \mathrm{C}$ under all loading rates was higher than that of the specimen processed under room temperature. The highest growth was close to $20 \%$ in the loading rate range of 20-50 $\mathrm{m} / \mathrm{s}$. The peak stress of the concrete specimen processed at $600{ }^{\circ} \mathrm{C}$ under all loading rates was lower than that of the specimen processed under room temperature. The maximum growth reached $25 \%$ with the increase in loading rate. The peak stress of the concrete specimen processed at $800{ }^{\circ} \mathrm{C}$ was $50 \%$ lower than that of the specimen processed under room temperature. In particular, the peak stress at $110 \mathrm{~m} / \mathrm{s}$ was lower than that at $8.6 \mathrm{~m} / \mathrm{s}$ mainly because the incompletely hydrated ingredients in the concrete materials were further hydrated before $400{ }^{\circ} \mathrm{C}$, which increased the material strength [37]. However, calcium hydroxides produced from the hydration of cements decomposed and were dehydrated after $600{ }^{\circ} \mathrm{C}$, accompanied with the decomposition of magnesium carbonate and calcium carbonate of dolomite and calcite in the aggregates. The aggregates lost their stability. The concrete surface was damaged and peeled off under a high temperature, resulting in serious damage. Many microcracks and internal defects were produced by such a weakening effect of thermal injuries, and the cement matrix and coarse aggregates weakened. These conditions can remarkably influence the strengthening effect of loading rate. In particular, the strengthening effect remarkably decreased under an ultrahigh loading rate $(>25 \mathrm{~m} / \mathrm{s})$.

\section{CONCLUSIONS}

Uniaxial testing and numerical simulation of concrete materials processed at high temperatures were conducted to determine the variation law of peak stress under all feasible loading rates $(10-110 \mathrm{~m} / \mathrm{s})$ in the SHPB system. Several major conclusions were obtained.

(1) The coupled effects of the weakening of thermal injury and strengthening of loading rate $(10-20 \mathrm{~m} / \mathrm{s})$ on peak stress were determined through an experimental study.
The two-peak phenomenon of stress-strain curves under compression loads was analyzed in terms of material failure and aggregate distribution.

(2) Through a numerical simulation analysis, the fragmentation degree of concrete specimens increased with the increase in heating temperature and loading rate. Material failure diffused from the centre to the edges.

(3) The numerical simulation of concrete specimens processed under different temperatures and at an ultrahigh loading rate $(20-110 \mathrm{~m} / \mathrm{s})$ demonstrated that the peak stress and loading rate initially increased then decreased. The close relationship between the weakening effect of thermal injury and loading rate was revealed.

In this study, the influencing law of high temperature and all feasible loading rates on the compression strength of concrete materials was investigated through testing and numerical simulation. The fragmentation characteristics of concrete materials were discussed. The research conclusions can provide theoretical references for the design of the ultimate strength of concrete materials for practical applications. Future studies can perform tests and numerical simulations in consideration of confining pressure.

\section{Acknowledgements}

This study was supported by National Natural Science Foundation of China (No. 41272286), the National Natural Science Foundation of China (No. 41772277), and the Fundamental Research Funds for the Central Universities (No. 310826172004).

\section{REFERENCES}

[1] Khosravani, M. R. \& Weinberg, K. (2018). A review on split Hopkinson bar experiments on the dynamic characterization of concrete. Construction and Building Materials, 190, 1264-1283. https://doi.org/10.1016/j.conbuildmat.2018.09.187

[2] Jia, B., Tao, J. L., Li, Z. L., Wang, R. H., \& Zhang, Y. (2008). Effects of Temperature and Strain Rate on Dynamic 
Properties of Concrete. Transactions of Tianjin University, 14(S1), 511-513. https://doi.org/10.1007/s12209-008-0087-6

[3] Wang, Z. G. \& Meyer, L. W. (2010). On the Plastic Wave Propagation along the Specimen Length in SHPB Test. Experimental Mechanics, 50(7), 1061-1074. https://doi.org/10.1007/s11340-009-9294-x

[4] Huo, J. S., Hey, M., Xiao, L. P. \& Chen, B. S. (2013). Experimental study on dynamic behaviors of concrete after exposure to high temperatures up to $700{ }^{\circ} \mathrm{C}$. Materials and Structures, 46, 255-265. https://doi.org/10.1617/s11527-012-9899-x

[5] Kolsky, H. (2002). An Investigation of the Mechanical Properties of Materials at very High Rates of Loading. Proceedings of the Physical Society, 62(11), 676. https://doi.org/10.1088/0370-1301/62/11/302

[6] Alsalloum, Y., Almusallam, T., Ibrahim, S. M., Abbas, H. \& Alsayed, S. (2015). Rate dependent behavior and modeling of concrete based on SHPB experiments. Cement \& Concrete Composites, 55, 34-44. https://doi.org/10.1016/j.cemconcomp.2014.07.011

[7] Liu, S. \& Xu, J. (2015). Effect of strain rate on the dynamic compressive mechanical behaviors of rock material subjected to high temperatures. Mechanics of Materials, 82(06), 28-38. https://doi.org/10.1016/j.mechmat.2014.12.006

[8] Zhu, T. T., Jing, H. W., Su, H. J., Yin, Q., Du, M. R., \& Han, G. S. (2016). Physical and mechanical properties of sandstone containing a single fissure after exposure to high temperatures. International Journal of Mining Science and Technology, 26(2), 319-325. https://doi.org/10.1016/j.jmst.2015.12.019

[9] Li, M., Mao, X. B., Cao, L. L., Pu, H., Mao, R. R., \& Lu, A. H. (2016). Effects of Thermal Treatment on the Dynamic Mechanical Properties of Coal Measures Sandstone. Rock Mechanics \& Rock Engineering, 49(9), 3525-3539. https://doi.org/10.1007/s00603-016-0981-5

[10] Fan, L. F., Wu, Z. J., Wan, Z., \& Gao, J. W. (2017). Experimental investigation of thermal effects on dynamic behavior of granite. Applied Thermal Engineering, 125, 94103. https://doi.org/10.1016/j.applthermaleng.2017.07.007

[11] Zhou, Z., Cai, X., Chen, L., Cao, W. H., Zhao, Y., \& Xiong, C. (2017). Influence of cyclic wetting and drying on physical and dynamic compressive properties of sandstone. Engineering Geology, 220, 1-12. https://doi.org/10.1016/j.enggeo.2017.01.017

[12] Li, Z., Xu, J., \& Bai, E. (2012). Static and dynamic mechanical properties of concrete after high temperature exposure. Materials Science \& Engineering, 544, 27-32. https://doi.org/10.1016/j.msea.2012.02.058

[13] Chen, L., Fang, Q., Jiang, X. Q., Ruan, Z., \& Hong, J. (2015). Combined effects of high temperature and high strain rate on normal weight concrete. International Journal of Impact Engineering, 86, 40-56. https://doi.org/10.1016/j.jijmpeng.2015.07.002

[14] Xiao, J. Z., Li, Z. W., Xie, Q. H., \& Shen, L. M. (2016). Effect of strain rate on compressive behaviour of highstrength concrete after exposure to elevated temperatures. Fire Safety Journal, 83, 25-37. https://doi.org/10.1016/j.firesaf.2016.04.006

[15] Kim, D. J., Sirijaroonchai, K., El-Tawil, S., \& Naaman, A. E. (2010). Numerical simulation of the split Hopkinson pressure bar test technique for concrete under compression. International Journal of Impact Engineering, 37(2), 141149. https://doi.org/10.1016/j.ijimpeng.2009.06.012

[16] Zhang, H., Xie, A. Y., \& Gao, Y. W. (2014). Numerical simulation of SHPB test for concrete under confining pressure. Applied Mechanics and Materials, 580-583, 31443148 .

https://doi.org/10.4028/www.scientific.net/AMM.580-583.3144
[17] Fakhimi, A., Azhdari, P., \& Kimberley, J. (2018). Physical and numerical evaluation of rock strength in split Hopkinson pressure bar testing. Computers and Geotechnics, 102, 1-11. https://doi.org/10.1016/j.compgeo.2018.05.009

[18] Jiang, S., Huang, M., \& Zhan, J. W. (2016). Numerical simulation on the SHPB test of argillaceous siltstone by using the LS-DYNA. Transactions of Nonferrous Metals Society of China, 68(2), 54-58.

[19] Ai, S., Tang, L., Mao, Y., Liu, Y. P. \& Fang, D. N. (2013). Numerical analysis on failure behavior of polyurethane polymer concrete at high strain rates in compression. Computational Materials Science, 69, 389-395. https://doi.org/10.1016/j.commatsci.2012.12.018

[20] Han, D. B. (2014). Study on dynamic fracture capabilities of rock materials and numerical simulation. Anhui University of Science and Technology, 2109-3115.

[21] Zhai, Y., Ai, X. Q., \& Deng, Z. C. (2014). Influences on cooling mode and high temperature concrete compressive strength. Journal of Hunan University (Natural Sciences), 41(11), 74-80.

[22] Zhai, Y., Li, Y. B., Li, Y., Jiang, W. Q., \& Liu, X. Y. (2018). Research on the Impact Loading and Energy Dissipation of Concrete after Elevated Temperature under Different Heating Gradients and Cooling Methods. Materials, 11(9), 1651. https://doi.org/10.3390/ma11091651

[23] Holmquist, T. J. \& Johnson, G. R. (2011). A Computational Constitutive Model for Glass Subjected to Large Strains, High Strain Rates and High Pressures. Journal of Applied Mechanics, 78(5), 1003. https://doi.org/10.1115/1.4004326

[24] Mai, S. H., Le-Corre F., Foret, G., \& Nedjar, B. (2012). A continuum damage modeling of quasi-static fatigue strength of plain concrete. International Journal of Fatigue, 37, 7985. https://doi.org/10.1016/j.ijfatigue.2011.10.006

[25] Dressen, T., Hegger, J., Will, N., \& Niewels, J. (2009). Static system of plain concrete basement walls under earth pressure. Magazine of Concrete Research, 61(10), 815-821. https://doi.org/10.1680/macr.2008.61.10.815

[26] Zhou, S. Z., Zhan, L., \& Liu, M. Q. (2016). Analysis on effect of aggregate on mechanical property of concrete. Journal of Building Materials, 19(01), 143-148.

[27] Hu, G. L., Liu, R. Z., Qi, A. D. \& Li, Z. C. (2005). SHPB experiment and dynamic properties of concrete. Journal of Nanjing University of Science and Technology, 29(04), 420424.

[28] Song, L. Z., Yuan, J., \& Gang, P. (2010) Numerical simulation of concrete random parameterized aggregate model and load test. Journal of Hydraulic Engineering, 41(10), 1241-1247.

[29] Hao, Y. \& Hao, H. (2011) Numerical evaluation of the influence of aggregates on concrete compressive strength at high strain rate. International Journal of Protective Structures, 2(2), 177-206 https://doi.org/10.1260/2041-4196.2.2.177

[30] Quas, M., Hummeltenberg, A., \& Curbach, M. (2012) High performance lightweight aggregate concrete under impact loading. Beton und Stahlbetonbau, 107(01), 422-426. https://doi.org/10.1002/best.201200013

[31] Wang, D., Guo, Z. K., Shao, F., \& Chen, W. X. (2014) Experimental study on dynamic mechanical properties of HPP hybrid fibers reinforced lightweight aggregate concrete. Advanced Materials Research, 919(921), 1983-1989. https://doi.org/10.4028/www.scientific.net/AMR.919-921.1983

[32] Li, Y., Tao, J. L., Gao, F., \& Li, K. (2012) Research on dynamic compressive failure criterion of concrete at high temperature. Advanced Materials Research, 446-449, 382385. https://doi.org/10.4028/www.scientific.net/AMR.446-449.382

[33] Liu, H. F. \& Han, L. (2015) Numerical Simulation Research on Dynamic mechanical behaviors of concrete subjected to 
impact loading. Chinese Journal of Solid Mechanics, 36(02), $145-153$.

[34] Xu, J. Y. \& Liu, S. (2013) Analysis of energy dissipation rule during deformation and fracture process of rock under high temperatures in SHPB test. Chinese Journal of Rock Mechanics and Engineering, 32, 3109-3115.

[35] Xie, H. P., Li, Y., Peng, R. D., \& Ju, Y. (2005) Criteria for strength and structural failure of rocks based on energy analysis of rock failure. Chinese Journal of Rock Mechanics and Engineering, 24(15), 2603-2608.

[36] Karakoç, M. B. (2013) Effect of cooling regimes on compressive strength of concrete with lightweight aggregate exposed to high temperature. Construction \& Building Materials, 41(2), 21-25. https://doi.org/10.1016/j.conbuildmat.2012.11.104

[37] He, Y., Yu, Q., Wang, P., \& He, Y. M. (2014) Dynamic behavior of normal-strength carbonate aggregate concrete at temperatures up to $800^{\circ} \mathrm{C}$. Magazine of Concrete Research, 66(19), 975-990. https://doi.org/10.1680/macr.14.00047

\section{Contact information:}

Yue ZHAI, PhD

School of Geology Engineering and Geomatics, Chang'an University, Room 311, No. 126 Yanta Road, No. 5 Teaching Building, 710064 X'an,

Shaanxi Province, China

E-mail: zy@chd.edu.cn

\section{Yi LIU}

School of Geology Engineering and Geomatics, Chang'an University,

Room 317, No. 126 Yanta Road, No. 5 Teaching Building, 710064 Xi'an,

Shaanxi Province, China

E-mail: ly@chd.edu.cn

Yubai LI, (corresponding author)

School of Earth Sciences and Resources, China University of Geosciences,

Room 630, No. 29 Xueyuan Road, Yifu Building, 100086 Beijing, China

E-mail: yubaili@cugb.edu.cn

Yan LI, PhD

School of Geology Engineering and Geomatics, Chang'an University,

Room 308, No. 126 Yanta Road, No. 5 Teaching Building, 710064 Xi'an,

Shaanxi Province, China

E-mail: lylwbdlp@chd.edu.cn

\section{Yunmei SHI}

School of Geology Engineering and Geomatics, Chang'an University,

Room 317, No. 126 Yanta Road, No. 5 Teaching Building, 710064 Xi'an,

Shaanxi Province, China

E-mail: yunmei_shi@163.com

\section{KI-IL SONG, PhD}

Department of Civil Engineering, Inha University,

100 Inha-ro, Nam-gu, 22002 Incheon, South Korea

E-mail: ksong@inha.ac.kr 